\title{
Evaluation of the inhibitory effects of drugs on the growth of Babesia gibsoni using relative quantification real-time PCR
}

\author{
He, W.H. ${ }^{1}$, Feng, X.X. ${ }^{2}$, Wu, X. ${ }^{2}$, Zhai, X.H. ${ }^{1}$, Li, Y.Y. ${ }^{1}$, Zhang, B. ${ }^{{ }^{*}}$ and Yao D.W. ${ }^{2^{*}}$ \\ ${ }^{1}$ Jiangsu Agri-Animal Husbandry Vocational College, Jiangsu Taizhou, 225300, China \\ ${ }^{2}$ College of Veterinary Medicine, Nanjing Agricultural University, Nanjing, Jiangsu, 210095, China \\ *Corresponding author e-mails: 149124273@qq.com, yaodawei@njau.edu.cn \\ Received 27 April 2020; received in revised form 13 August 2020; accepted 14 August 2020
}

\begin{abstract}
To evaluate the inhibitory effects of drugs on the growth of Babesia gibsoni, relative quantification real-time PCR method was developed in this study. The $18 S$ rRNA gene was used as a target gene for the $2^{-\Delta \Delta C t}$ method analysis. Additionally, chicken RNA was added to the parasitized blood before total RNA extraction. The chicken $\beta$-actin gene was selected as an internal control gene for the $2^{-\Delta \Delta \mathrm{Ct}}$ method analysis. The $100 \mu \mathrm{L}$ parasitized blood samples with different percentages of parasitized erythrocytes (PPEs) (3\%, 1.5\%, 0.75\%, $0.375 \%$ and $0.1875 \%$ ) were prepared for relative quantification of $B$. gibsoni. Regression analysis results revealed significant linear relationships between the relative quantification value and parasitemia. $18 S$ rRNA gene expression was significantly decreased after treatment with diminazene aceturate and artesunate in vitro drug sensitivity test. This result suggested that this relative quantification real-time PCR method can be used to evaluate the effects of drug inhibition.
\end{abstract}

\section{INTRODUCTION}

Babesia is transmitted by ticks to vertebrates and results in severe economic losses in the livestock industry worldwide. Human babesiosis is also global problem, and presenting a significant health burden in areas where it is endemic (Tonnetti et al., 2019). Babesia gibsoni infection occurs frequently in dogs and has recently become a serious problem because this disease typically results in severe clinical problems (fever, thrombocytopenia, regenerative anemia, splenomegaly, and sometimes death) and recurrent infections even after treatment with antibabesia drugs (Goo \& Xuan, 2014). Several antibabesia drugs have been in use for many years, such as diminazene aceturate, imidocarb dipropionate, artesunate, atovaquone, and atovaquone with azithromycin (Goo et al., 2010; Checa et al., 2017; Tuvshintulga et al.,
2019). However, most drugs have proven to be ineffective because of problems related to toxicity and the development of resistant parasites (Mosqueda et al., 2012; Checa et $a l .$, 2017). Therefore, the development of more effective drugs against Babesia with low toxicity to hosts has is desired.

At present, there is no recognized standard in practice for drug screening or activity evaluation. More recently, in vitro assays have been proposed to determine the susceptibilities of Babesia to drugs (Matsuu et al., 2008; AbouLaila et al., 2010; Silva et al., 2013; Rizk et al., 2017). Parasite-infected red blood cells (RBCs) were diluted with uninfected RBCs to obtain the RBC stock with parasitemia. Then, RBCs with parasitemia were cultured in medium containing the indicated concentration of drugs and incubated at $37^{\circ} \mathrm{C}$ in a humidified multigas water-jacketed incubator. The sensitivity against drugs was evaluated by measuring 
the rate of parasite growth inhibition. The rate of parasitism was calculated by counting the parasitized RBCs to approximately 1000 RBCs in Giemsia-stained thin blood smears. However, microscopic examination of Giemsia-stained thin blood smears requires good-quality smears, and significant differences in parasitemia estimated by different personnel may be found (Rizk et al., 2015).

mRNA has been used as a marker of viability, as it is a highly labile molecule with a very short half-life. Therefore, mRNA can provide a closely correlated indication of viability status. Ribosomal RNA (rRNA) has also been investigated as an indicator of viability (Villarino et al., 2000) and has been found to be positively correlated with viability under some bacterial-killing regimens (McKillip et al., 1998). In this research, we used the $18 S$ rRNA gene of B. gibsoni as a molecular target for relative quantification using real-time PCR.

\section{MATERIALS AND METHODS}

\section{Chemical reagents}

Diminazene aceturate and artesunate were purchased from Macklin Ltd. (Shanghai, China). Stock solutions of $20 \mathrm{mM}$ were prapared in physiological saline and stored at $-20^{\circ} \mathrm{C}$ until use.

\section{Parasites}

B. gibsoni parasites were isolated from a naturally infected dog in Nanjing, China. This parasite was identified as B. gibsoni according to $18 \mathrm{~S}$ rRNA gene sequence analysis (Yao et al., 2014). The blood from the sick dog naturally infected with $B$. gibsoni was kept in liquid nitrogen. Then, this blood was subinoculated into a beagle. Parasites were first detected in blood from the beagle 12 days after inoculation. The blood used in this research was collected from the beagle infected with $B$. gibsoni. Samples were collected in strict accordance with the recommendations in the Guide for the Care and Use of Laboratory Animals of Jiangsu Province. The protocol was approved by the Committee on the Ethics of Animal Experiments of JiangSu Agri-Animal Husbandry Vocational College (20180801).

\section{B. gibsoni relative quantification assay}

Parasitized blood was collected from a beagle. Blood smears were made and stained with Wright-Giemsa. The percentage of parasitized erythrocytes was calculated by enumeration of 1,000 total infected and uninfected RBCs on Wright-Giemsa smears at $1,000 \times$ under oil using microscopy. Parasitized blood was diluted using uninfected blood collected from normal dog. One hundred microliters of parasitized blood samples with different PPEs (3\%, 1.5\%, $0.75 \%, 0.375 \%$ and $0.1875 \%$ ) was used for RNA isolation. Three micrograms of chicken RNA isolated from spleen tissue were added to each blood sample and mixed together before RNA extraction. The total RNA of the mixture was extracted using RNAiso Plus reagent (Takara, Japan) according to the manufacturer's instructions, and the RNA concentration was measured using a NanoDrop 2000 spectrophotometer (Thermo Fisher Scientific Inc., USA). Reverse transcription-PCR was conducted using a PrimeScript One-Step RT-PCR kit (Takara, Japan) according to the manufacturer's instructions. One primer pair ( $\beta$-actin F 5 'GAGAATTGTG CGTGACATCA-3' and $\beta$-actin R 5'-CCTGAACCTCTCATTGCC A-3') was used to amplify a $157 \mathrm{bp}$ fragment of the chicken $\beta$-actin gene (Yao et al., 2016). Another primer pair (B.com $339 \mathrm{~F}$ 5'-GTCTTGTAATTGGAATGATGGTGAC-3' and B.com 339 R 5'-ATGCCCCCAA CCGTTCCTATTA$3^{\prime}$ ) was used to amplify a $339 \mathrm{bp}$ fragment of the 18S rRNA gene of Babesia gibsoni (Yao et al., 2014). Real-time PCR was performed with an Applied Biosystems 7500 Real-time PCR System (Applied Biosystems, USA). The cDNA synthesized from B. gibsoni and chicken RNA were diluted continuously to generate calibration curves. PCR amplification efficiencies of the $B$. gibsoni $18 S$ rRNA gene and chicken $\beta$-actin gene were established by means of calibration curves. The expression levels of the $18 S$ $r R N A$ gene, which indicated the quantity of 
B. gibsoni, were analyzed with the $2^{-\Delta \Delta \mathrm{Ct}}$ method. Each test was performed in triplicate. The 3\% PPE group was identified as the control.

The quantity of B. gibsoni was calculated according to Eq. 1 .

$-\Delta \Delta \mathrm{C}_{\mathrm{T}}=-\left[\left(\mathrm{C}_{\mathrm{T} 18 \text { SrRNA of B.g }}-\mathrm{C}_{\mathrm{T} \beta \text {-actin of chicken }}\right)\right.$ test group - $\left(\mathrm{C}_{\mathrm{T} 18 \mathrm{SrRNA} \text { of } B . g}-\mathrm{C}_{\mathrm{T} \beta \text {-actin of chicken }}\right)$ control group]

where $\mathrm{C}_{\mathrm{T} 18 \mathrm{SrRNA} \text { of } B . g}$ was the value of the $B$. gibsoni $18 S$ rRNA gene. $\mathrm{C}_{\mathrm{T} \beta \text {-actin of chicken was }}$ the value of the chicken $\beta$-actin gene.

\section{Drug sensitivity test}

For the in vitro drug sensitivity test, $100 \mu \mathrm{L}$ parasitized blood with $3 \%$ PPE and $200 \mu \mathrm{L}$ of artesunate (880 nM, $220 \mathrm{nM}$ and $55 \mathrm{nM}$, respectively) were distributed per well in 24-well plates with three replicates per concentration. These plates were incubated at $37^{\circ} \mathrm{C}$ for $24 \mathrm{~h}$. RNAiso Plus reagent and 3 $\mu \mathrm{g}$ chicken RNA were added to the well for total RNA extraction. Real-time PCR was used for B. gibsoni relative quantification, and the $0 \mathrm{nM}$ group was identified as the control. Different concentrations of diminazene aceturate solution $(800 \mathrm{nM}, 80$ $\mathrm{nM}$ and $8 \mathrm{nM}$ ) were used for the in vitro drug sensitivity test as well.

\section{Statistical analysis}

The data in the figure are presented as the arithmetic mean \pm standard deviation (SD). The statistical analysis was performed by one-way analysis of variance (ANOVA) using Predictive Analytics Software 18.0. Duncan's multiple-range test was used, with differences considered to be significant at $P<0.05$.

\section{RESULTS}

\section{B. gibsoni relative quantification assay} The melting curve of the B. gibsoni $18 S$ rRNA gene and chicken $\beta$-actin gene indicated that the primers used in this study were specific for real-time PCR amplification. The PCR amplification efficiencies of B. gibsoni $18 S$ $r R N A$ gene and chicken $\beta$-actin gene were
97.7\% and $96.7 \%$, respectively. These results suggested that the real-time PCR used in this study was reliable. $B$. gibsoni relative quantification is shown in the Figure 1. The magnitude of linearity ranged from $0.375 \%$ to $3 \%$ PPE. The equation of the parasitized blood volume versus the $B$. gibsoni relative quantification obtained was $\mathrm{y}=0.323 \mathrm{x}$ with an $R^{2}$ of 0.987 . Significant linear relationships between the relative quantification and parasitemia were observed.

\section{Drug sensitivity test for artesunate}

The expression levels of the 18S rRNA gene in the artesunate-treated group were downregulated compared to those in the control group $(P<0.05)$. The levels of the $18 S$ $r R N A$ gene were $27 \%$ lower at $880 \mathrm{nM}$ artesunate (Figure 2). It was suggested that B. gibsoni was significantly suppressed in the presence of $55 \mathrm{nM}, 220 \mathrm{nM}$ and $880 \mathrm{nM}$ artesunate. The higher the concentration of artesunate used, the better the inhibitory effects achieved were. Artesunate can dosedependently inhibit B. gibsoni in vitro.

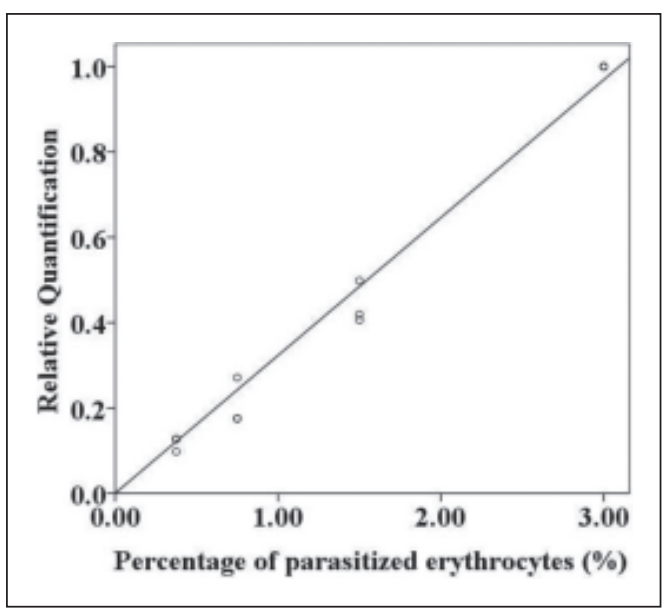

Figure 1. Linearity assessment between B. gibsoni relative quantification and percentage of parasitized erythrocytes. Chicken RNA was added to each blood sample before RNA extraction, and the chicken $\beta$-actin gene was selected as an internal control. The $18 S$ rRNA gene expression levels of each blood sample with different PPEs (3\%, 1.5\%, 0.75\%, 0.375\% and $0.1875 \%$ ) were analyzed with the $2^{-\Delta \Delta \mathrm{Ct}}$ method. The group of $3 \%$ PPE was identified as the control. 


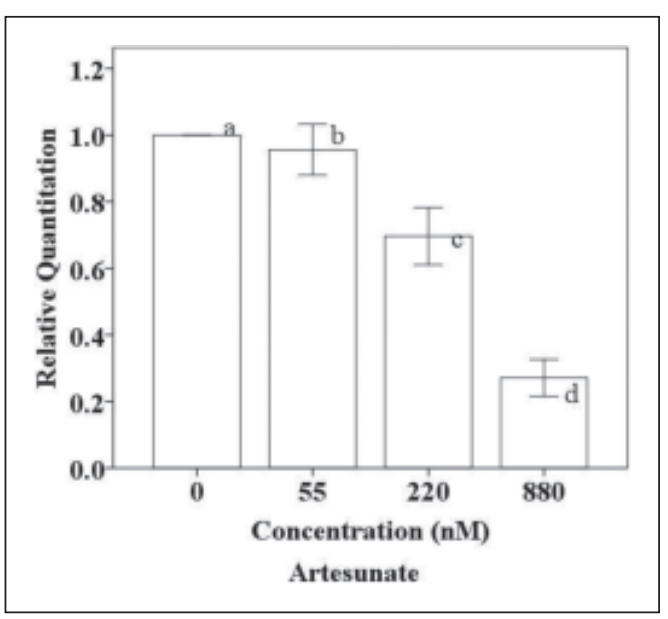

Figure 2. Drug sensitivity test of artesunate. The parasitized blood samples were treated with artesunate (880 $\mathrm{nM}, 220 \mathrm{nM}$ and $55 \mathrm{nM})$ and incubated at $37^{\circ} \mathrm{C}$ for $24 \mathrm{~h}$. The $18 S \mathrm{rRNA}$ gene expression levels of each blood sample were analyzed with the relative quantification real-time PCR method. The $0 \mathrm{nM}$ group was identified as the control. Different letters indicate statistically significant differences $(P<0.05)$.

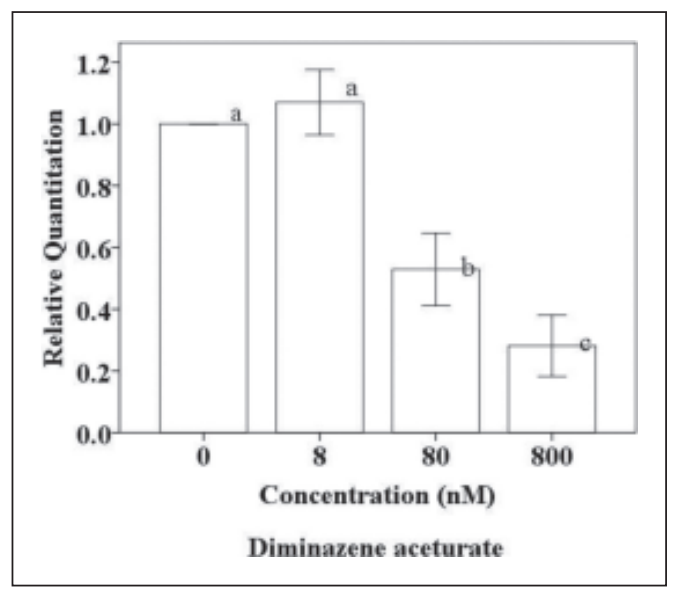

Figure 3. Drug sensitivity test of diminazene aceturate. The parasitized blood samples were treated with diminazene aceturate $(800 \mathrm{nM}, 80$ $\mathrm{nM}$ and $8 \mathrm{nM}$ ) and incubated at $37^{\circ} \mathrm{C}$ for $24 \mathrm{~h}$. The 18S rRNA gene expression levels of each blood sample were analyzed with the relative quantification real-time PCR method. The $0 \mathrm{nM}$ group was identified as the control. Different letters indicate statistically significant differences $(P<0.05)$.

\section{Drug sensitivity test for diminazene aceturate}

The expression levels of the $18 S r R N A$ gene in the diminazene aceturate-treated group (80 $\mathrm{nM}, 800 \mathrm{nM}$ ) were downregulated compared to those in the control group and the $8 \mathrm{nM}$ diminazene aceturate-treated group $(P<0.05)$ (Figure 3$)$. Interestingly, the expression levels were found to be significantly reduced (28\%) in the presence of artesunate $800 \mathrm{nM}(P<0.05)$. The lower concentration of diminazene aceturate $(8 \mathrm{nM})$ had no inhibitory effects.

\section{DISCUSSION}

In recent years, due to the toxicity and resistance of drugs, the development of new drugs that have a chemotherapeutic effect against babesiosis with high specificity to the parasites and low toxicity to the host is urgently needed. Moreover, the development of a simple in vitro system to the test susceptibility of Babesia to such drugs is important. Reverse transcription combined with polymerase chain reaction has proven to be a powerful method for quantifying gene expression. Relative quantification real-time PCR describes the change in expression of the target gene relative to a reference group. The method used to present quantitative realtime PCR data was the comparative CT method, also known as the $2^{-\Delta \Delta \mathrm{Ct}}$ method. Using this method, the data are presented as the fold change in gene expression normalized to an endogenous reference gene and relative to the untreated control (Livak \& Schmittgen, 2001). For the untreated control sample, $\Delta \Delta \mathrm{Ct}$ equals zero and $2^{\circ}$ equals 1 , so that the fold change in gene expression relative to the untreated control equals 1 , by definition. Housekeeping genes usually suffice as internal control genes and are not affected by experimental treatment. Suitable internal controls for real time quantitative PCR include GAPDH, $\beta$-actin, and $r R N A$. 
In this research, the $18 S$ rRNA gene was used as target gene to quantifiy the parasites. It has been reported that the mRNA transcripts of the B. bovis tubulin beta chain and small subunit rRNA genes are not affected by treatment with lower concentrations of apicoplast-targeting antibacterials (AbouLaila et al., 2012). Due to the instability of mRNA, the nucleic acid degraded when the parasites died. Therefore, mRNA could provide a more closely correlated indication of the viability status of the parasites.

In this research, the $18 S \mathrm{rRNA}$ gene of B. gibsoni parasites was selected as the target gene rather than the internal control gene. Because of degradation of mRNA, no gene can be used as an internal control gene. In this study, chicken RNA was added to the parasite RNA and the $\beta$-actin gene of chicken was selected as an internal control gene. The same quantity of chicken RNA was added to both the treated group and untreated control group to confirm the same quantification expression of $\beta$-actin gene. The quantity of B. gibsoni were calculated according to the equation where $-\Delta \Delta \mathrm{C}_{\mathrm{T}}=-\left[\left(\mathrm{C}_{\mathrm{T}}\right.\right.$ 18SrRNA of $B . g-$ $\left.\mathrm{C}_{\mathrm{T} \beta \text {-actin of chicken }}\right)$ test group - $\left(\mathrm{C}_{\mathrm{T}}\right.$ 18SrRNA of B.g $-\mathrm{C}_{\mathrm{T} \beta \text {-actin of chicken }}$ ) control group].

Significant linear relationships between the relative quantification value and parasitemia were observed using the real-time PCR method. To evaluate the inhibitory effects of the drug, diminazene aceturate and artesunate were added to the parasitized blood. The $18 S r R N A$ gene expression was decreased relative to that in the untreated control. Both diminazene aceturate and artesunate can dose-dependently inhibit the growth of B. gibsoni in vitro.

Microscopic examination of Giemsiastained thin blood smears was widely used in evaluation of inhibitory effects of antibabesia drugs. However, this method was influenced by the quality of the blood smears as well as the skill and experience of experimentators (Rizk et al., 2015). Incorporation of radioactive substances had been a common method in in vitro antimalarial drug screening. This method is slowly being replaced by a fluorescence- based method because the former was constrained by problems with disposing of radioactive materials (Quashie et al., 2006; Rizk et al., 2015). These methods must need in vitro cultures of Babesia parasites for about 4 days. In this study, relative quantification real-time PCR was used for drug evaluation against Babesia gibsoni without continuous culture. The lower parasitemia level can also be detected in real-time PCR method. This assay was easier to perform and was found to be reliable and sensitive.

\section{CONCLUSIONS}

In summary, relative quantification real-time PCR for RNA was developed in this study. This method can differentiate live parasites and be used to evaluate inhibitory effects on the growth of Babesia gibsoni.

Acknowledgements. The work was supported by JiangSu Agri-Animal Husbandry Vocational College Academy Research Project (NSF20180801) and JiangSu University Brand Specialty Construction Work Founded Project (PPZY2015C230).

\section{Conflict of Interests}

The authors declare that they have no conflict of interests.

\section{REFERENCES}

AbouLaila, M., Munkhjargal, T., Sivakumar, T., Ueno, A., Nakano, Y., Yokoyama, M., Yoshinari, T., Nagano, D., Katayama, K., El-Bahy, N., Yokoyama, N. \& Igarashi, I. (2012). Apicoplast-targeting antibacterials inhibit the growth of Babesia Parasites. Antimicrobial Agents and Chemotherapy 56: 3196-3206.

AbouLaila, M., Nakamura, K., Govind, Y., Yokoyama, N. \& Igarashi, I. (2010). Evaluation of the in vitro growthinhibitory effect of epoxomicin on Babesia parasites. Veterinary Parasitology 167: 19-27. 
Checa, R., Montoya, A., Ortega, N., Luis Gonzalez-Fraga, J., Bartolome, A., Galvez, R., Marino, V. \& Miro, G. (2017). Efficacy, safety and tolerance of imidocarb dipropionate versus atovaquone or buparvaquone plus azithromycin used to treat sick dogs naturally infected with the Babesia microti-like piroplasm. Parasites and Vectors 10: 145.

Goo, Y.-K., Terkawi, M.A., Jia, H., Aboge, G.O., Ooka, H., Nelson, B., Kim, S., Sunaga, F., Namikawa, K., Igarashi, I., Nishikawa, Y. $\&$ Xuan, X. (2010). Artesunate, a potential drug for treatment of Babesia infection. Korean Jourmal of Parasitology 59: 481486.

Goo, Y.-K. \& Xuan, X. (2014). New molecules in Babesia gibsoni and their application for Diagnosis, Vaccine Development, and Drug Discovery. Korean Journal of Parasitology 52: 345-353.

Livak, K.J. \& Schmittgen, T.D. (2001). Analysis of relative gene expression data using real-time quantitative PCR and the $2(\mathrm{~T})$ (-Delta Delta C) method. Methods 25: 402408.

Matsuu, A., Yamasaki, M., Xuan, X., Ikadai, H. \& Hikasa, Y. (2008). In vitro evaluation of the growth inhibitory activities of 15 drugs against Babesia gibsoni (Aomori strain). Veterinary Parasitology 157: 18.

McKillip, J.L., Jaykus, L.A. \& Drake, M. (1998). rRNA stability in heat-killed and UVirradiated enterotoxigenic Staphylococcus aureus and Escherichia coli O157: H7. Applied and Environmental Microbiology 64: 4264-4268.

Mosqueda, J., Olvera-Ramirez, A., AguilarTipacamu, G. \& Canto, G.J. (2012). Current advances in detection and treatment of babesiosis. Current Medicinal Chemistry 19: 1504-1518.

Quashie, N.B., de Koning, H.P. \& RanfordCartwright, L.C. (2006). An improved and highly sensitive microfluorimetric method for assessing susceptibility of Plasmodium falciparum to antimalarial drugs in vitro. Malaria Journal 5: 95.
Rizk, M.A., El-Sayed, S.A.E.-S., AbouLaila, M., Yokoyama, N. \& Igarashi, I. (2017). Evaluation of the inhibitory effect of N-acetyl-L-cysteine on Babesia and Theileria parasites. Experimental Parasitology 179: 43-48.

Rizk, M.A., El-Sayed, S.A.E.-S., Terkawi, M.A., Youssef, M.A., El Said, E.S.E.S., Elsayed, G., El-Khodery, S., El-Ashker, M., Elsify, A., Omar, M., Salama, A., Yokoyama, N. \& Igarashi, I. (2015). Optimization of a fluorescence-based assay for large-scale drug screening against Babesia and Theileria Parasites. PlosOne 10: e0125276

Silva, M.G., Domingos, A., Alexandra Esteves, M., Cruz, M.E.M. \& Suarez, C.E. (2013). Evaluation of the growth-inhibitory effect of trifluralin analogues on in vitro cultured Babesia bovis parasites. International Journal for ParasitologyDrugs and Drug Resistance 3: 59-68.

Tonnetti, L., Townsend, R.L., Deisting, B.M., Haynes, J.M., Dodd, R.Y. \& Stramer, S.L. (2019). The impact of Babesia microti blood donation screening. Transfusion 59: $593-600$.

Tuvshintulga, B., Sivakumar, T., Yokoyama, N. \& Igarashi, I. (2019). Development of unstable resistance to diminazene aceturate in Babesia bovis. International Journal for ParasitologyDrugs and Drug Resistance 9: 87-92.

Villarino, A., Bouvet, O.M.M., Regnault, B., Martin-Delautre, S. \& Grimont, P.A.D. (2000). Exploring the frontier between life and death in Escherichia coli: evaluation of different viability markers in live and heat- or UV-killed cells. Research in Microbiology 151: 755-768.

Yao, D.-W., Jiang, J.-Y., Yu, Z.-Z., Yao, D.-Q., Yang, D.-J. \& Zhao, Y.-B. (2014). Canine babesiosis in China caused by Babesia gibsoni: a molecular approach. Iranian Journal of Parasitology 9: 163-168.

Yao, D.-W., Zhan, L., Hong, Y.-F., Liu, J.-X., Xu, J.-R. \& Yang, D.-J. (2016). Altered expression of the mismatch repair genes in DF-1 cells infected with the avian leukosis virus subgroup A. Springerplus 5: 1756. 